\title{
Post-traumatic biliobronchial fistula demonstrated on hepatobiliary scintigraphy with SPECT/CT
}

\author{
Anish Bhattacharya - Koramadai Karuppuswamy Kamaleshwaran • \\ Chidambaram Natarajan Balasubramaniam Harisankar • Kuruva Manohar • \\ Mohammed Labeeb Abrar • Bhagwant Rai Mittal
}

Received: 28 May 2010 / Accepted: 30 June 2010 /Published online: 21 July 2010

(C) Springer-Verlag 2010

A 22-year-old male patient suffered a grade IV liver injury with haemoperitoneum in a roadside accident 2 months earlier, for which laparotomy and biliary stenting were done. However, after a few days, the stent was passed during defecation. A week later, the patient developed intractable cough with copious expectoration of green sputum. Chest X-ray showed right-sided pleural effusion with consolidation in the right lower lobe. Sputum examination confirmed the presence of bile, which raised the suspicion of a biliobronchial communication.

$\left[{ }^{99 \mathrm{~m}} \mathrm{Tc}\right]$ Mebrofenin hepatobiliary scintigraphy (HBS) showed preserved function in the right lobe of the liver and impaired uptake in the left lobe (a). Static planar images from $45 \mathrm{~min}$ to $2 \mathrm{~h}(\mathrm{~b}, \mathrm{c})$ showed unobstructed biliary drainage into the intestine caudally, with a streak of tracer passing cranially into the chest cavity (arrowhead) and subsequently taking the shape of the central airways (arrow). Hybrid SPECT/CT imaging (d, e, f) identified radiotracer in the bronchi and trachea (arrow).

Bronchobiliary fistula is an unusual complication of thoracoabdominal trauma $[1,2]$. Clinically, patients present with fever, dyspnoea, cough and biliptysis. The latter is pathognomonic of fistula formation, and large volumes of bright yellow sputum may be encountered [3]. Previous studies have shown planar HBS to be a reliable noninvasive investigation to identify post-traumatic biliopleural and biliobronchial communications $[4,5]$. In this case,

\footnotetext{
A. Bhattacharya $(\triangle) \cdot K$. K. Kamaleshwaran $\cdot$

C. N. Balasubramaniam Harisankar $\cdot$ K. Manohar • M. L. Abrar •

B. R. Mittal

Department of Nuclear Medicine,

Postgraduate Institute of Medical Education \& Research, Chandigarh 160012, India

e-mail: anishpgi@yahoo.co.in
}
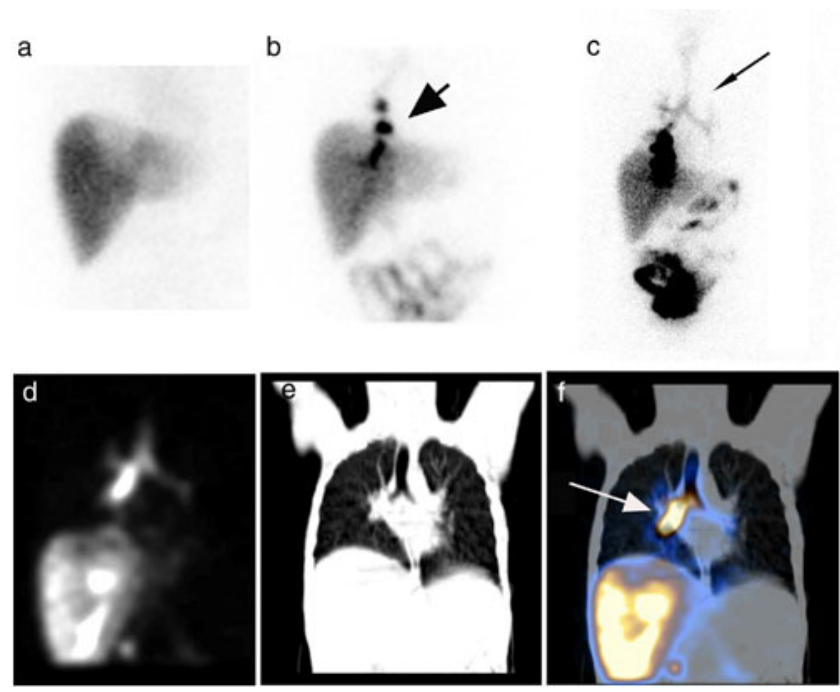

SPECT/CT clearly defined the fistulous tract from the right lobe of the liver to the respiratory tract.

Conflicts of interest None.

\section{References}

1. Oparah SS, Mandal AK. Traumatic thoracobiliary (pleurobiliary and bronchobiliary) fistulas: clinical and review study. J Trauma 1978;18:539-44

2. Ivatury RR, O'Shea J, Rohman M. Post-traumatic thoracobiliary fistula. J Trauma 1984;24:438-42.

3. Koch KA, Crump JM, Monteiro CB. A case of biliptysis. J Clin Gastroenterol 1995;20:49-53.

4. Bhattacharya A, Gupta R, Mittal BR. Traumatic biliopleural communication detected by hepatobiliary scintigraphy. Clin Nucl Med 2006;31:170-1.

5. Santra A, Kumar R, Maharjan S, Bal C, Malhotra A. Traumatic bronchobiliary fistula diagnosed by $99 \mathrm{mTc}-$ mebrofenin hepatobiliary scintigraphy. Nucl Med Commun 2009;30:652-3. 